Tropical Journal of Pharmaceutical Research July 2017; 16 (7): 1703-1709

ISSN: $1596-5996$ (print); 1596-9827 (electronic)

(C) Pharmacotherapy Group, Faculty of Pharmacy, University of Benin, Benin City, 300001 Nigeria.

All rights reserved.

Available online at http://www.tjpr.org

Original Research Article

http://dx.doi.org/10.4314/tjpr.v16i7.31

\title{
A study on the interaction between metformin and constituents of a commercial herbal product
}

\author{
Matthew I Arhewoh, Sylvester O Eraga*, Jonah Irabor and Magnus A Iwuagwu \\ Department of Pharmaceutics and Pharmaceutical Technology, Faculty of Pharmacy, University of Benin, PMB 1154, Benin
} City, 300001, Nigeria

*For correspondence: Email: eragaso@uniben.edu; Tel: +234-8030884928

Sent for review: 29 November 2016

Revised accepted: 29 April 2017

\begin{abstract}
Purpose: To investigate the interactions between metformin and Yoyo Bitters $\AA$ including some of its constituents in the management of diabetes mellitus.

Method: Using the generic form of metformin (Glucophage $\left.\mathbb{B}^{3}\right)$ tablets, tests such as disintegration time, dissolution profile, Fourier transform infrared (FTIR) spectroscopy and in vivo hypoglycaemia tests using Wistar albino rat were performed for metformin to investigate its behaviour in the presence and absence of Yoyo Bitters and some plant extracts used in its formulation.

Results: Metformin tablets used met BP specification in terms of pharmaceutical properties. There was no significant change in the disintegration properties of the metformin tablets in the presence of Yoyo Bitters $(p>0.05)$ while a significant change occurred in the dissolution profile $(p<0.05)$. The FTIR spectra showed some level of interactions due to disappearance of some spectral peaks. In vivo result showed a significant reduction $(p<0.05)$ in the duration of action of metformin.

Conclusion: Concomitant administration of metformin and Yoyo Bitters showed interaction that appeared antagonistic to the hypoglycaemic effect of metformin both in vitro and in rat models
\end{abstract}

Keywords: Metformin, In vitro interactions, Yoyo Bitters, Diabetes

Tropical Journal of Pharmaceutical Research is indexed by Science Citation Index (SciSearch), Scopus, International Pharmaceutical Abstract, Chemical Abstracts, Embase, Index Copernicus, EBSCO, African Index Medicus, JournalSeek, Journal Citation Reports/Science Edition, Directory of Open Access Journals (DOAJ), African Journal Online, Bioline International, Open-J-Gate and Pharmacy Abstracts

\section{INTRODUCTION}

Herb-drug interaction results from the coadministration of a herbal product and a conventional drug. These interactions can be synergistic or antagonistic in nature. Herbal-drug interactions have also been reported to alter the absorption, distribution, metabolism and elimination of conventional drugs [1].

The rational use of herbal medicines is of particular importance because the majority of these products are self-prescribed and often used to treat minor and sometimes chronic conditions. However, most patients consuming herbal preparations are not aware of the toxic or potential adverse effects these preparations may produce [2-5] or any form of interactions associated with the use of such products when co-administered with orthodox medicine [6,7].

Some known herb-drug interactions have been reported to be negative in nature, such as concomitant administration of garlic and warfarin which leads to prolonged bleeding [8-10], while some interactions may have beneficial effect on drug therapy. For example, rhubarb and mirabilitum, which are purgatives, have been reported to produce more reliable and stronger purgative action when used together [11].

Metformin is a well-known oral hypoglycaemic drug used in the management of type 2 diabetes 
mellitus. Yoyo Bitters ${ }^{\circledR}$ is an herbal tonic widely used in Nigeria with claims of detoxification, helps to reduce body fat and consequently enhances weight loss. Some of its constituents includes Aloe vera and Citrus aurantifolia (key lime). Aloe vera is claimed to have wound healing, anti-microbial, anti-tumour, anti-aging, anti-inflammatory, anti-septic, anti-viral and antidiabetic properties [12,13]. Citrus aurantifolia has been reported to have antioxidant effect [14] and used traditionally as a worm expeller, antimicrobial, anti-cancer, anti-parasitic agents as well as for weight loss, colds and arthritis [13]. There are undocumented reports by the vendors of Yoyo Bitters of its use by some diabetic patients that are already on commonly used oral hypoglycaemic drugs. They believe that Yoyo Bitters improve their well-being without any particular justification for this belief except that the herbal product is natural and claims to do so. This study was carried out to investigate any form of interaction between metformin and Yoyo Bitters and some of its constituents during concomitant administration of the drugs.

\section{EXPERIMENTAL}

\section{Materials}

Metformin powder was a gift sample from Springs Nigerian Enterprises, Lagos, Nigeria, Hydrochloric acid was obtained from May and Baker, England. Citrus aurantifolia (key lime) and Aloe vera were obtained from the botanical garden of the Faculty of Pharmacy, University of Benin. Plant samples were identified and authenticated by Dr Joseph Erhabor and voucher specimen numbers (UBH_r0282 and UBH_x0169a, respectively) were assigned. The plant samples were kept in the herbarium of the Department of Plant Biology and Biotechnology, University of Benin, Nigeria. Glucophage ${ }^{\circledR}$ tablets and Yoyo Bitters ${ }^{\circledR}$ were purchased from a Pharmacy in Benin City, Nigeria. Their labelled information are shown in Table 1.

\section{Preliminary physicochemical evaluation of tablets}

Metformin (Glucophage ${ }^{\circledR}$ ) tablets containing 500 $\mathrm{mg}$ of metformin hydrochloride were subjected to some preliminary physicochemical evaluations such as physical examination, organoleptic properties, weight uniformity, friability and crushing strength using standard procedures [15].

\section{Weight uniformity}

Twenty (20) metformin tablets were randomly selected and weighed (Mettler Toledo, Switzerland) and the mean weight was computed. The percentage deviation of each individual tablet weight was also calculated from the mean.

\section{Friability}

Ten (10) tablets were randomly selected, dusted and weighed together and then placed in the Roche friabilator and operated for $4 \mathrm{~min}$ at 25 rpm. The tablets were de-dusted and reweighed and the percentage weight loss calculated.

\section{Crushing strength}

Using a motorized tablet hardness tester (Campbell Electronics, Model HT-30/50, India), the hardness of each of ten tablets was determined by diametrial compression of the tablets and the mean crushing strength value was calculated.

\section{Interaction studies}

\section{Disintegration test}

The time taken for six metformin tablets to disintegrate in $500 \mathrm{~mL}$ distilled water at $37 \pm 1.0$ ${ }^{\circ} \mathrm{C}$ and for the particles to pass through the mesh of the BP disintegration tester (MK IV, Manesty Machines, UK) was determined. The mean or average time was calculated. The test was repeated using $500 \mathrm{~mL}$ of distilled water-Yoyo Bitters mixture. The mixture was prepared by making up $30 \mathrm{~mL}$ of Yoyo Bitters to $500 \mathrm{~mL}$ with distilled water. This $30 \mathrm{~mL}$ is the recommended adult dose based on information obtained from the product label.

\section{Dissolution test}

The dissolution test of metformin tablets was carried out using the BP paddle method.

Table 1: Labelled information of the metformin tablets and Yoyo Bitters ${ }^{\circledR}$ used in the study

\begin{tabular}{cccccc}
\hline $\begin{array}{c}\text { Brand } \\
\text { name }\end{array}$ & $\begin{array}{c}\text { Batch/ } \\
\text { Lot No. }\end{array}$ & $\begin{array}{c}\text { NAFDAC } \\
\text { No. }\end{array}$ & $\begin{array}{c}\text { Manufacture } \\
\text { Date }\end{array}$ & $\begin{array}{c}\text { Expiry } \\
\text { date }\end{array}$ & $\begin{array}{c}\text { Country of } \\
\text { manufacture }\end{array}$ \\
\hline Glucophage & Y00060 & $04-6233$ & $02 / 2015$ & $01 / 2020$ & Nigeria \\
Yoyo Bitters & NBR 1520 & A7-10552 & $06 / 2015$ & $07 / 2017$ & Nigeria \\
\hline
\end{tabular}


A dissolution apparatus (Caleva ST7, UK) containing $500 \mathrm{~mL}$ solution of phosphate buffer $\mathrm{pH} 6.8$ maintained at $37 \pm 1.0^{\circ} \mathrm{C}$ with a paddle speed of $50 \mathrm{rpm}$ was used. A tablet selected at random was placed in the dissolution vessel and operated over a period of $60 \mathrm{~min}$. A $5 \mathrm{~mL}$ sample was withdrawn from the dissolution fluid at specific time intervals and replaced with an equivalent volume of fresh fluid maintained at same temperature $\left(37 \pm 1.0^{\circ} \mathrm{C}\right)$ in order to maintain sink condition. The withdrawn samples were filtered and subjected to UVspectrophotometric analysis at $\lambda$ max of $232 \mathrm{~nm}$ (T70, PG Instruments Ltd). The amount and the percentage of drug released at each time interval was calculated by extrapolation from the standard calibration plot obtained from pure metformin powder.

The test was repeated using $500 \mathrm{~mL}$ of phosphate buffer containing $30 \mathrm{~mL}$ of Yoyo Bitters.

\section{Absorbance interference study}

\section{Metformin alone}

A quantity of metformin powder equivalent to 100 $\mathrm{mg}$ was dissolved in $50 \mathrm{~mL}$ of $0.1 \mathrm{~N} \mathrm{HCl}$ solution in a $100 \mathrm{~mL}$ volumetric flask. The volume was made up to $100 \mathrm{~mL}$ with more $0.1 \mathrm{~N} \mathrm{HCl}$ solution to obtain a metformin stock solution of 1.0 $\mathrm{mg} / \mathrm{mL}$. Gradient metformin standard concentrations ranging from 2.0 to $10 \mu \mathrm{g} / \mathrm{mL}$ were prepared from the stock solution using 0.1 $\mathrm{N} \mathrm{HCl}$ solution and subjected to ultra-violet spectrophotometric analysis at $232 \mathrm{~nm}$. Triplicate readings were taken and the mean of the respective absorbance was calculated. A plot of absorbance vs metformin concentration was drawn.

\section{Metformin plus either Yoyo Bitters, Aloe vera or Citrus aurantifolia}

The Yoyo Bitters was first of all dried in a porcelain dish over a hot water bath until a $1 \mathrm{~g}$ dried residue was obtained. Metformin-Yoyo Bitters stock solution was then prepared by dissolving $100 \mathrm{mg}$ of metformin powder and $1 \mathrm{~g}$ of the dried Yoyo Bitters residue in $50 \mathrm{~mL}$ of 0.1 $\mathrm{N} \mathrm{HCl}$ solution and made up to $100 \mathrm{~mL}$. Serial dilutions of the metformin-Yoyo Bitters mixture ranging from 2.0 to $10 \mu \mathrm{g} / \mathrm{mL}$ of metformin were prepared using $0.1 \mathrm{~N} \mathrm{HCl}$ as diluent.

For Aloe vera, the bark of the leaves was removed with a kitchen knife and the juice extracted after blending. The juice was dried in a porcelain dish over a thermostated water bath.
One gram of the dried juice residue was diluted with $0.1 \mathrm{~N} \mathrm{HCl}$ solution to $100 \mathrm{~mL}$, left overnight and filtered. The filtrate was then used to serially dilute metformin stock solution $(1.0 \mathrm{mg} / \mathrm{mL} 0.1 \mathrm{~N}$ $\mathrm{HCl}$ solution) into a range of concentrations (2.0 to $10 \mu \mathrm{g} / \mathrm{mL}$ of metformin). The dilutions were shaken intermittently for $30 \mathrm{~min}$ and thereafter left to stand for another $30 \mathrm{~min}$.

Similarly, juice from lime fruits was extracted using a juice extractor. The extracted juice was dried in a porcelain dish over a thermostated water bath and $1 \mathrm{~g}$ of the dried product was added to $100 \mathrm{mg}$ of metformin powder and made up to $100 \mathrm{~mL}$ with $0.1 \mathrm{~N} \mathrm{HCl}$ solution to give a metformin-Citrus aurantifolia stock solution. The stock solution was left to stand for $1 \mathrm{~h}$ with intermittent shaking and then serially diluted with more $0.1 \mathrm{~N} \mathrm{HCl}$ solution to a range of concentrations from 2.0 to $10 \mu \mathrm{g} / \mathrm{mL}$ of metformin.

All the samples prepared and their respective dilutions were analysed spectrophotometrically in triplicates at $232 \mathrm{~nm}$ and their mean values plotted against their concentrations to obtain a line of regression.

\section{FTIR analysis}

Dried Yoyo Bitters powder, pure metformin powder and their admixture were subjected to FTIR analysis using the potassium bromide tablet method (FTIR-4100 Spectrophotometer, Shimadzu Co. Japan). Five milligram powder sample was blended with dried potassium bromide to give a $200 \mathrm{mg}$ weight powder. The powder was compressed using a Sigma potassium bromide press into a tablet, and then placed in the sample compartment of the spectrophotometer and scanned at a range of $4000-750 \mathrm{~cm}^{-1}$.

\section{Animal studies}

Healthy Wistar Albino rats of both sex, with mean weight of $225 \mathrm{~g}$ were purchased from the Department of Biochemistry, University of Benin and allowed to acclimatize for two weeks in the animal house of the Department of Pharmacology and Toxicology, Faculty of Pharmacy, University of Benin, Benin City. Ethical approval for the study was obtained from the Ethical Committee on the Use of Animals for Experiments, Faculty of Pharmacy, University of Benin, Benin City, Nigeria. The animals were treated according to the principle established for the care and use of laboratory animals [16]. Diabetes was induced using a single dose of 150 $\mathrm{mg} / \mathrm{kg}$ streptozotocin, administered intraperito- 
neally in $0.05 \mathrm{M}$ citrate buffer solution $\mathrm{pH} 4.5$ [17]. The animals were left for $72 \mathrm{~h}$ and in order to prevent hypoglycemic shock within the first 24 $\mathrm{h}$, the animals were administered with $10 \%$ glucose solution orally. After $72 \mathrm{~h}$, experimental diabetes was confirmed in the rats using the AccuChek Active glucometer (Roche, USA) and fasting blood glucose level greater than 200 $\mathrm{mg} / \mathrm{dL}(11.1 \mathrm{mmol} / \mathrm{L})$ was taken as being diabetic [18].

The diabetic animals fasted overnight were divided into four groups (A-D) of five animals each. They had free access to water prior to the experiment. Using an orogastric syringe, groups $A$ and $B$ rats were orally given an aqueous stock solution of metformin at a dose of $100 \mathrm{mg}$ per $\mathrm{kg}$ body weight. Thereafter, a dose of $15.49 \mathrm{~kg} / \mathrm{mL}$ of Yoyo Bitters (a median oral dose) was given to groups $B$ and $C$ rats [19]. The last group of rats (control) was given $10 \mathrm{~mL}$ of distilled water.

Blood samples were obtained from the animals using the tail snipping method over a period of 5 $\mathrm{h}$ following a single drug administration for all the groups of animals. Blood glucose level was determined immediately after sampling using the glucometer and expressed at a percentage of the initial level, prior to drug administration.

\section{Statistical analysis}

Inferential statistical evaluation was done using GraphPad InStat software version 3.10. One-way analysis of variance (ANOVA) was determined at a $p<0.05$ level of significance using Dunnett's multiple comparison test.

\section{RESULTS}

\section{Preliminary tablet evaluation}

Results from the preliminary evaluations carried out on the metformin (Glucophage ${ }^{\circledR}$ ) tablets are presented in Table 2. The tablets were elegant in their organoleptic appeal and showed a mean weight variation, percentage friability and mean crushing strength values that meets the BP specifications with regards to these parameters [15].
Table 2: Some physicochemical properties of metformin (Glucophage ${ }^{\circledR}$ ) tablets (mean \pm SD)

\begin{tabular}{ll}
\hline Tablet property & Result \\
\hline Colour & White \\
Surface texture & Smooth \\
Taste & Slightly bitter \\
Inscriptions & GL 500 \\
Mean weight $(\mathrm{mg})$ & $530 \pm 0.007$ \\
Friability $(\%)$ & 0.25 \\
Mean crushing strength $(\mathrm{kp})$ & $6.96 \pm 0.120$ \\
\hline
\end{tabular}

\section{Interaction data}

\section{Disintegration and dissolution}

The results from the interaction studies on the effect of Yoyo Bitters on the disintegration time and dissolution profile of metformin tablets are shown in Table 3 and Figure 1. The disintegration times of the metformin tablets in distilled water and in the presence of Yoyo Bitters was the same (Table 3). The dissolution profile of the tablets in phosphate buffer was not the same as in the phosphate buffer-Yoyo Bitters mixture (Figure 1) with different metformin release pattern and maximum drug release. The tablets showed a maximum metformin release $\left(\mathrm{m}_{\infty}\right)$ of $73.6 \%$ within $60 \mathrm{~min}$ with phosphate buffer as the dissolution medium as against a $47.5 \%$ release in the phosphate buffer-Yoyo Bitters mixture. The tablets achieved 50 and 70 $\%$ release in 46 and $55 \mathrm{~min}$ respectively in phosphate buffer.

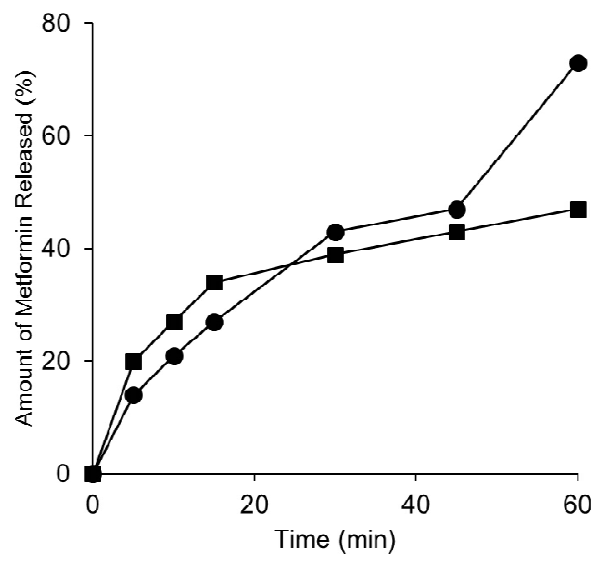

Figure 1: Dissolution profiles of metformin tablets in the absence of Yoyo Bitters $(\bullet)$ and presence of Yoyo Bitters (

Table 3: Disintegration and dissolution release parameters of metformin (Glucophage ${ }^{\circledR}$ ) tablets in the absence or presence of Yoyo Bitters

\begin{tabular}{lccc}
\hline Parameter & & Absence of Yoyo bitters & Presence of Yoyo bitters \\
\hline \multicolumn{2}{l}{ Disintegration time $(\mathrm{min})$} & $1.56 \pm 0.82$ & $1.56 \pm 0.66$ \\
\hline \multirow{2}{*}{ Dissolution } & $\mathrm{m}_{\infty}(\%)$ & $73.6 \pm 0.22$ & $47.5 \pm 0.48$ \\
parameters & $\mathrm{t}_{50 \%}(\mathrm{~min})$ & $46 \pm 0.36$ & - \\
& $\mathrm{t}_{70 \%}(\mathrm{~min})$ & $55 \pm 0.44$ & - \\
\hline
\end{tabular}

Values are mean \pm standard deviation 


\section{Absorbance}

A comparison of the absorbance of the various dilutions of the stock solutions of metformin and the mixtures of metformin with either Yoyo Bitters, Aloe vera or Citrus aurantifolia is shown in Figure 2. The extract altered the UV absorbance of metformin in a non-specific manner. Metformin alone showed a linear increase in absorbance that was proportional to the concentration from 2 to $8 \mu \mathrm{g} / \mathrm{mL}$, while the presence of Yoyo Bitters showed an initial decline in absorbance at 2 and $4 \mu \mathrm{g} / \mathrm{mL}$ followed by a much higher increase in absorbance at 6 and $8 \mu \mathrm{g} / \mathrm{mL}$. Citrus aurantifolia on the other hand gave a steady concentration based decline in metformin absorbance while Aloe vera resulted in total disappearance in metformin absorbance. Values obtained at $10 \mu \mathrm{g} / \mathrm{mL}$ did not show any linearity.

\section{FTIR spectra}

Spectra from the FTIR analysis are shown in Figure 3. The spectrum obtained from metformin (Figure 3 (a)) exhibits numerous peaks. A comparison of the spectra of Yoyo Bitters (Figure 3 (b)) and the admixture of metformin and Yoyo Bitters (Figure 3 (c)) with that of metformin shows a significant reduction in the number of peaks of the metformin spectrum, an indication of a possible interaction.

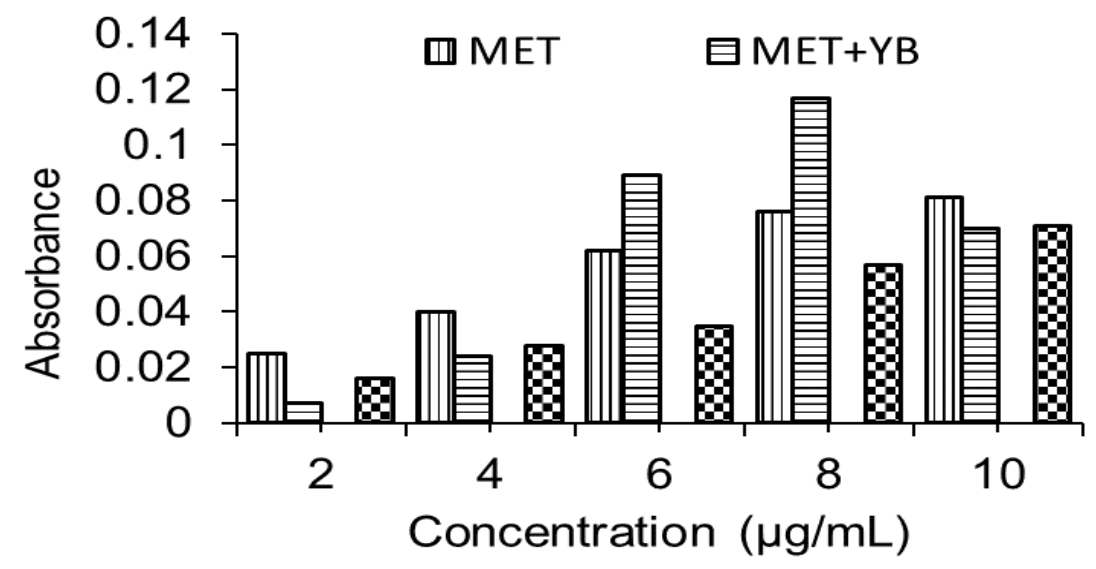

Figure 2: A comparison of the absorbances of the serial dilutions of stock solutions of metformin (MET) and a mixture of metformin with either Yoyo Bitters (YB), Aloe vera (AV) or Citrus aurantifolia (CA)

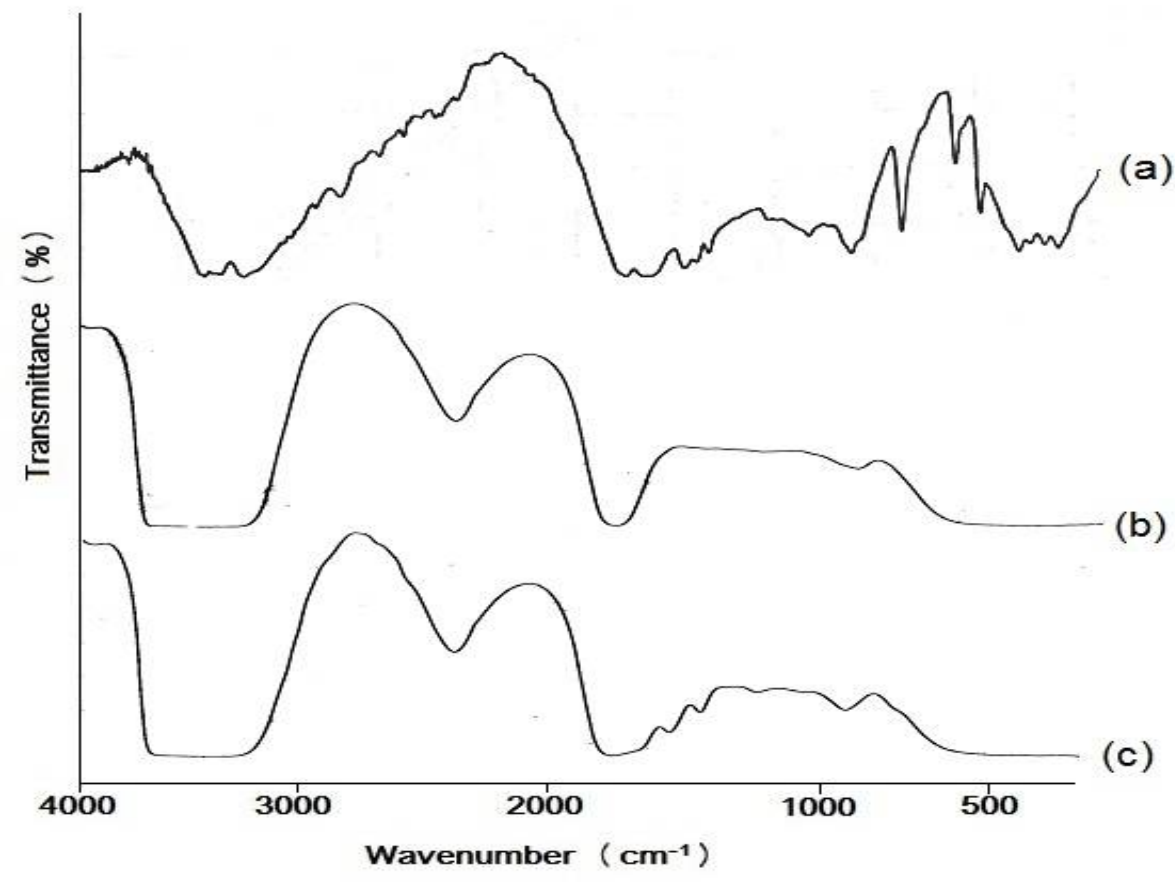

Figure 3: FTIR spectra of metformin alone (a), Yoyo Bitters (b) and the admixture of metformin and Yoyo Bitters (c) 


\section{In vivo interaction}

Results from the in vivo interaction study between metformin and Yoyo Bitters in streptozotocin-induced hyperglycaemic rats are shown in Figure 4. There was a significant reduction in hyperglycaemia $(p<0.05)$ in all the metformin and Yoyo Bitters treated groups after a single oral administration of the drugs. However, groups treated with the mixture of metformin and Yoyo Bitters had their hypoglycaemia reversed after $3 \mathrm{~h}$ while metformin alone continued to show reduction in blood glucose up to $5 \mathrm{~h}$ of the study. Yoyo Bitters alone showed reduction in blood glucose which was reversed after $4 \mathrm{~h}$ of study.

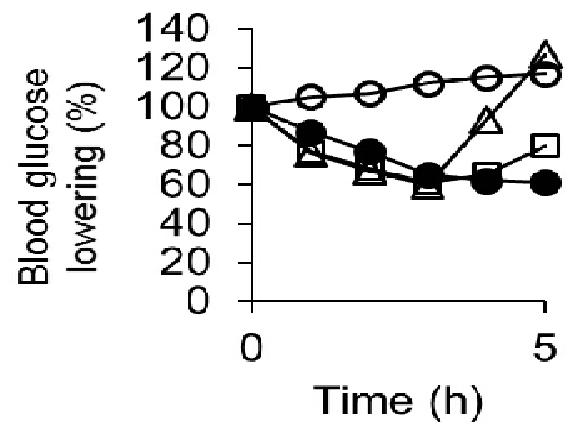

Figure 4: Percentage blood glucose lowering in diabetic animals administered metformin alone $(\bullet)$, Yoyo Bitters $(\square)$, a mixture of metformin and Yoyo Bitters $(\Delta)$ and distilled water $(O)$

\section{DISCUSSION}

Herb-drug interactions are usually not easily detectable at the initial stage of physical blending of the herbs and drugs. Hence there appeared to be no significant change to the physical parameters of metformin tablets [6]. Further investigations of dissolution studies showed a difference in the dissolution profiles of metformin tablets alone and in the presence of Yoyo-bitters. There was evidence of an initial increased rate of dissolution in the presence of Yoyo Bitters but with time the rate of dissolution was reduced.

The absorbance results show that this initial increase may be as a result of interference by Yoyo Bitters since at 6 to $8 \mu \mathrm{g} / \mathrm{mL}$, there was a remarkable increase in the absorbance of the mixtures. The rate of dissolution in distilled water increased steadily and $73.6 \%$ of metformin was dissolved in $1 \mathrm{~h}$ while in the presence of Yoyo Bitters, only $47.5 \%$ of metformin was dissolved in the medium suggesting that the presence of Yoyo Bitters affected the dissolution profile of metformin tablets [7]. This would likely be due to saturation of the dissolution medium by the components of Yoyo bitters which results in slowing down the dissolution rate of metformin from tablets. The absorbance test showed an increase in the absorbance of metformin at its wavelength in the presence of Yoyo Bitters and some of its constituents. This is probably due to the presence of components that have close or same wavelength of absorbance as metformin.

The presence of Citrus aurantifolia showed that there was no significant change in the absorbance of metformin while in the presence of Aloe vera, there was no noticeable absorbance reading for metformin showing that $A$. vera interfered significantly with metformin, so that its presence could not be detected in the mixture by the UV-spectrophotometer. While the cause of this interference is not very clear, it may be helpful to investigate further based on the components of $A$. vera plant. It is also likely that the $A$. vera constituents of Yoyo Bitters may have been responsible for the significant level of observable interactions.

In vivo hypoglycaemic activity which was performed on rats showed a reduction in glucose levels from the first hour to the third hour for all the treated groups ( $A$ to $C$ ), but at the fifth hour, only metformin continued to reduce the blood glucose levels. The blood glucose lowering activity of Yoyo Bitters was not sustained after the third hour while that of metformin was steady and sustained even till the fifth hour [19]. The mixture resulted in early reversal of hypoglycaemia noticed at the fourth hour. This reversal infer that although both agents caused hypoglycaemia, the interaction showed antagonism on the hypoglycaemic action of the metformin by Yoyo bitters. The reason for the reduction in duration of action of metformin might be explained from the FTIR results where the components of Yoyo biters mask the functional group responsible for the prolonged action of metformin leading to reduced duration of action of the metformin as seen in the study. Another possibility is the metformin/Yoyo bitters competitive binding to receptor site for drug action due to similarity in the nature of some constituents. There is the possibility of constituents of Yoyo bitters displacing metformin and thereby leading to a reduction and their hypoglycaemic activity.

\section{CONCLUSION}

Yoyo Bitters exerts blood glucose-lowering activity in streptozotocin-induced diabetic rats. Furthermore, when given concomitantly with metformin, it results in the reduction in the hypoglycaemic activity of metformin. Although there was no change in the disintegration time, there was evident interaction in the dissolution 
profile of the metformin tablets. Furthermore, Aloe vera, which is a constituent of Yoyo Bitters, may be responsible for the interaction seen. The concomitant administration of metformin and Yoyo Bitters leads to interaction that is antagonistic to the hypoglycaemic effect of metformin in rat models.

\section{DECLARATIONS}

\section{Acknowledgement}

We acknowledge the assistance rendered by the laboratory staff of the Department of Pharmaceutics and Pharmaceutical Technology, Faculty of Pharmacy, University of Benin, Benin City.

\section{Conflict of Interest}

No conflict of interest associated with this work.

\section{Contribution of Authors}

The authors declare that this work was done by the authors named in this article and all liabilities pertaining to claims relating to the content of this article will be borne by them.

\section{Open Access}

This is an Open Access article that uses a funding model which does not charge readers or their institutions for access and distributed under the terms of the Creative Commons Attribution License (http://creativecommons.org/licenses/by/ 4.0) and the Budapest Open Access Initiative (http://www.budapestopenaccessinitiative.org/rea d), which permit unrestricted use, distribution, and reproduction in any medium, provided the original work is properly credited.

\section{REFERENCES}

1. Chavez ML, Jordan MA. Chavez PI. Evidence-based drug-herbal interactions. Life Sci 2006; 78: 2146-2157.

2. Joshua AJ, Goudar KS, Sameera N, Kumar GP, Murali B, Dinakar N, Amit A. Safety assessment of herbal formulations, Rumbion ${ }^{T M}$ and Tyrel ${ }^{T M}$ in albino wistar rats. Am J Pharmacol Toxicol 2010; 5(1): 42-47.

3. Obi E, Akunyili DN, Ekpo B, Orisakwe OE. Heavy metal hazards of Nigerian herbal remedies. Sci Total Environ 2006; 369(1-3): 35-41.

4. Ekor M, Odusoga AO, Adesina OO, Adewale GB, Kolawole SO. Toxicity evaluation of Yoyo cleanser bitters and fields Swedish bitters herbal preparations following sub-chronic administration in rats. Am J Pharmacol Toxicol 2010; 5: 159-166.

5. Esimone CO, Akah PA, Nworu CS. 2011. Efficacy and safety assessment of $T$. angelica herbal tonic, a phytomedicinal product popularly used in Nigeria. Evid Based Complement Alternat Med 2011; (Article ID: 123036): 6 pages.

6. Igbinoba SI, Adehin A, Onyeji CO, Akanmu MA, Soyinka JO. In vitro study of interaction between quinine and Garcinia kola. Trop J Pharm Res 2016; 15(7): 14731478.

7. Eraga SO, Idemili NO, Iwuagwu MA. In-vitro interaction between zidovudine and some adsorptive antacids. Dhaka Univ J Pharm Sci 2014; 13(1): 1-6.

8. German K, Kumar U, Blackford HN. Garlic and the risk of TRUP bleeding. Bri J Urol 1995; 76(4): 518.

9. Rose $K D$, Croissant $P D$, Parliament $C F$, Levin $M B$. Spontaneous spinal epidural hematoma with associated platelet dysfunction from excessive garlic ingestion: a case report. Neurosurgery 1990; 26(5): 880-882.

10. Morris J, Burke V, Mori TA, Vandongen R, Beilin LJ. Effects of garlic extract on platelet aggregation: a randomized placebo-controlled double-blind study. Clin Exp Pharmacol Physiol 1995; 22(6-7): 414-417.

11. Dharmananda S. The Interactions of Herbs and Drugs, Institute for Traditional Medicine, Portland, Oregon, 2000 [cited 2016 Oct 2]. Available from: http://www. itmonline.org/arts/herbdrug.htm

12. Sahu PK, Giri DD, Singh $R$, Pandey $P$, Gupta $S$, Shrivastava AK, Kumar A, Pandey KD. Therapeutic and medicinal uses of Aloe vera: A review. Pharmacol Pharm 2013; 4: 599-610.

13. Ezuruike UF, Prieto JM. The use of plants in the traditional management of diabetes in Nigeria: Pharmacological and toxicological considerations. J Ethnopharmacol 2014; 155(2): 857-924.

14. Guimarães R, Barros L, Barreira JC, Sousa MJ, Carvalho $A M$, Ferreira IC. Targeting excessive free radicals with peels and juices of citrus fruits: grapefruit, lemon, lime and orange. Food Chem Toxicol 2010; 48(1): 99-106.

15. British Pharmacopoeia Vol. I and II. London: The Pharmaceutical Press, Her Majesty's Stationery Office; 2003. p. 249-252.

16. National Institute of Health. Office of Laboratory Animal Welfare - Public Health Service Policy on Humane Care and Use of Laboratory Animals, Revised ed, USA. 2015.

17. Abeeleh MA, Ismail ZB, Alzaben KR, Abu-Halaweh SA, Al-Essa MK, Abuabeeleh J, Alsmady MM. Induction of diabetes mellitus in rats using intraperitoneal streptozotocin: A comparison between two strains of rats. Eur J Sci Res 2009; 32(3): 398-402.

18. Rheney CC, Kirk JK. Performance of three blood glucose markers. Ann Pharmacother 2000; 34(3): 317-321.

19. Jimmy EO, Udofia, AJ. Yoyo bitters, a potent alternative drug in the treatment of diabetes. Int $J$ Innov Med Health Sci 2014; 2: 1-5. 